\title{
Deliberating about race as a variable in biomedical research
}

\author{
Anton A van Niekerk
}

Race as a variable in research ethics is investigated: to what extent is it morally appropriate to regard the race of research subjects as pivotal for research outcomes? The challenges it poses to deliberation in research ethics committees are considered, and it is concluded that race sometimes must be considered, subject to clearly stated qualifications.

S Afr Med J 2011;101:248-250.
'Race' in research ethics is a thoroughly contested social construct and concept, and how it is understood and applied is not self-evident or clear. Race as a variable in a research protocol needs a rational and democratic deliberation, as its admissibility can seldom be settled by alleged 'hard scientific facts'. Hegel proposes deliberation of the sciences that produces rational beliefs that are not a matter of turns of phrase, allusiveness, half utterances and silences, but consist in the unambiguous, determinate and open expression of their meaning and significance. ${ }^{1}$

A conceptual analysis of deliberation and the intellectual processes required when encountering race in research ethics is provided, and whether this has constructive implications is investigated.

The literature on deliberation, and deliberative democracy in particular, includes the work of Jürgen Habermas, ${ }^{2-4}$ John Rawls, ${ }^{5}$ Jon Elster, ${ }^{6}$ James Bohman, ${ }^{7}$ Amy Gutman and Dennis Thompson, ${ }^{8}$ Diego Gambetta ${ }^{9}$ and James Fearon. ${ }^{10}$ Susan Stokes defines deliberation in terms of outcomes: 'the endogenous change of preferences resulting from communication;; ${ }^{11}$ Diego Gambetta's definition is based on aspects of the process: 'a conversation whereby individuals speak and listen sequentially before making a collective decision'; ${ }^{\prime 2}$ Joshua Cohen writes of 'free and public reasoning among equals'; ${ }^{13}$ and James Fearon defines deliberation as a discussion with intrinsically good results. ${ }^{14}$ I prefer Jon Elster's definition that highlights its democratic and deliberative dimensions; it is a form of '... collective decision making with the participation of all who will be affected by the decision or their representatives: this is the democratic part', and refers to '... decision making by means of arguments offered by and to participants who are committed to the values of rationality and impartiality: this is the deliberative part. ${ }^{15}$

The democratic character of truly deliberative processes is striking. A deliberation is a conversation in which all participants have an equal say and converse about a contested outcome. Participants are assumed to be free, equal and rational as outlined by Rawls, with his idea of negotiations about justice behind a veil of ignorance, ${ }^{16}$ and Habermas, with his idea of the ideal speech situation as the regulative idea guiding the accomplishment of all meaningful speech acts. ${ }^{17}$ Participants are assumed to have comparable levels of education, the same information and a common commitment to the process.

Secondly, a democratic process of deliberation is public. However, this has less to do with its general visibility and accessibility to the general public, and more with incorporating the 'public use of

Anton A van Niekerk, MA, BTh, DPhi

Centre for Applied Ethics, Stellenbosch University, W Cape reason' into discourse. 'Deliberation is public to the extent that these [institutional] arrangements permit free and open dialogue among citizens, who make informed and reasoned judgments about ways to resolve problematic situations. ${ }^{18}$ It represents a joint social activity and its publicness acknowledges, as claimed by Richard Rorty, the priority of process over substance; the 'priority of democracy over philosophy', i.e. the priority of the 'Socratic commitment to free exchange of views' over the 'Platonic commitment to the possibility of universal agreement. ${ }^{19}$ The ongoing process of a free exchange of ideas and insights, and not assuming that every deliberative process can and will yield a definitive and universally agreed upon conclusion, are important. The public deliberative process means the ability and willingness to repeat whatever argument in any form of public, even if that does not need to happen. This is less an empirical than a logical and regulative characteristic of the process.

Thirdly, deliberation occurs in a group that agrees to the procedural assumptions of the process. Therefore the group should be the creation of an institutional mechanism such as a research ethics committee (REC), which significantly contributes to the discipline required to proceed deliberatively. Deliberation is demanding and requires courage and perseverance. It does not come naturally, since people are naturally inclined to promote self-interest and short-term concerns; fortunately, this is diluted by the publicness of the process. For a group deliberative conversation to be successful meticulous procedural rules are not required, but it relies on co-operation implying forfeiting the promotion of own interests and insights. Causes of its failure include showing up late at meetings, not paying attention to what is said, jumping the queue, all speaking at once, and shouting (particularly in the absence of any argument). Fearon states that 'discussion, as a means of revealing private information, can be effective only when the number of the group do not understand themselves to have widely divergent or conflicting interests. ${ }^{20}$ This represents a significant challenge when race is the issue.

Elements of the Socratic dialogue (for a comprehensive analysis of Socratic dialogue, as distinguished from Sophist debate, see Van Niekerk ${ }^{21}$ ), largely a one-on-one exercise, can enhance the effect in deliberation. The Socratic docta ignorantia represents an attitude, not of initially knowing nothing (we all know something when entering dialogue), but of acknowledging the mutual partiality, fragmentation and fallibility of whatever knowledge we might think to have of a matter. This opens us to other insights and to learn from our interlocutors. When willing to learn from others we realise the limitations of our own views. Gambetta warns against the 'claro' (the Spanish word for 'obvious') culture that easily takes hold of partners in deliberation; the disposition to say 'I knew it all along; nothing you say surprises me!' - which belittles those who express an argument. ${ }^{22}$ Openness to other views distinguishes dialogue from debate: in debates, we wish to persuade and to win over to our non-negotiable position; in dialogue, we want to learn rather than persuade. It differs from bargaining, in which interests 
are promoted by threats and promises, or voting, in which views are simply aggregated. Deliberation informed by the ideals of Socratic dialogue unmasks the risks inherent in others' positions, or welcomes that risks be identified in my views. Ideally it leads to an often unforeseen new creative achievement that was not the position of anyone at the beginning. The most important Socratic aspect of deliberation is that decision-making ought to be the outcome of a transformation of views, rather than simply the aggregation (and possible misrepresentation) of preferences. The end or telos reached will differ from the respective initial insights of each individual in the group. It amounts to choosing between available alternatives and creating new alternatives. ${ }^{23}$ Deliberation should spur and actively promote the imagination. Its outcome should transform opinion, even if that does not transform society, as wished for by Karl Marx.

Deliberation should not necessarily aim at defining a final truth. It is more prudent to acknowledge that, at most, deliberation pursues a series of progressive settlements, achieved in the light of available information and the dialectical engagement of different ideas.

\section{Race and research proposals}

Deliberating about race in evaluating research proposals is daunting as the spectre of race, prejudice and discrimination is a haunting and destructive force in South Africa's history, from which it cannot be divorced. ${ }^{24}$ The emotions and experiences raised by the phenomenon of race should not be underestimated. Antjie $\mathrm{Krog}^{25}$ analyses the difficulties of so intensely identifying with people of another race that one actually can become one of them: 'I want to be part of the country I was born in. I need to know whether it is possible for somebody like me to become like the majority, to become "blacker?" and live as a full and at-ease component of the South African psyche ... How do I "flee" towards black ... if I have never cared to know what black means ... is it possible for a white person like myself, born in Africa, raised in a culture with strong Western roots, drenched in a political dispensation that said black people were different and therefore inferior ... to move towards a "blackness" as black South Africans themselves understand it?' She refers to Njabulo Ndebele, who said that 'white people in South Africa have a unique opportunity to remove themselves from under the umbrella of the international sanctity of the white body and share the vulnerability of the black body. ${ }^{26}$ Since that requires a better understanding of the vulnerability of the black body, she realises that race has to do with more than skin colour ${ }^{27}$ race is not primarily an appearance but an experience, a resistance, the challenge of 'otherness' that is not comfortably accommodated in the realm of familiar society. Her 'struggle for blackness' is not necessarily positive. 'The strangeness is real, [as is] the fact that I cannot ever really enter the psyche of somebody else, somebody black. The terror and loneliness of that inability is what I [nevertheless] don't want to give up on.28

Empathy with the dehumanising way in which race was dealt with is not simple. In an REC discussion we cannot suddenly shed our cultural and societal baggage in racial thinking. However, the structured and disciplined context of an REC supports our efforts to overcome prejudice and to engage in a conversation where, in the hope expressed by Habermas, the only force that prevails will be the superior rational argument. Krog refers to John Rawls: 'He says that you don't have to assume a common moral framework in the multicultural and liberal world of today to have stable political community. It is better to find a structure that can carry a variety of moral frameworks. He says ... it is almost impossible for such diverse groupings to find a common moral framework, but it is possible to design a framework that can survive the tension and renegotiations of different frameworks. One can agree through overlapping consensus, even if not for the same reasons.29 The structured setting of the REC contributes to the attainment of this possibility.

The democratic nature of deliberation and that equal partners participate in it is equally important for considering racial issues in REC meetings. Special efforts must be made to accept people's bona fides, despite the fact that this does not come naturally. Despite Krog's existential ruminations, we must accept that the way people think is not a function or a consequence of their skin colour. Committees should be cautious of discrimination on the basis of skin colour denying somebody the ability and opportunity to contribute meaningfully, e.g. 'You are white/black, therefore you don't know what you are talking about'.

We should insist that the democratic basis of deliberation demands that any issue, including race, must be fully faced and addressed when introduced as a variable in a protocol. Race permeates the social, cultural, political and public debate in South Africa. Although we know that race often is a social construct, this is difficult to undo. To deal with race, an REC should acknowledge its reality and sensitivity, establish as many relevant facts as possible for consideration, suspend judgement as long as possible, and at decision-time construct an argument that one is willing to repeat in any public context.

Several research articles ${ }^{30-33}$ deny the relevance of race as a marker in biomedical research. Schwartz claims that 'race is a social construct and not a scientific classification' and quotes a position paper of the American Anthropological Association: 'It has become clear that human populations are not unambiguous, clearly demarcated, biologically distinct groups ... Throughout history whenever different groups have come into contact, they have interbred. The continued sharing of genetic materials has maintained humankind as a single species ... Any attempt to establish lines of division among biological populations is both arbitrary and subjective. ${ }^{33}$ Bloche asserts that race is an 'ill-defined, indeed undefined' marker in health care research and criticises an African American Heart Failure Trial (A-HeFT) that included patients who were self-identified as 'black. ${ }^{31}$

RECs must note this literature, but that does not mean that the matter may be more complicated and that race could be a significant marker in certain studies. A case study 'Modeling the epidemiologic transition: energy expenditure, obesity and diabetes' (METS), that was discussed at a research ethics seminar of the IRENSA (International Research Ethics Network of South Africa) programme at the University of Cape Town, quoted literature that argues for acknowledging the relevance of race in explaining diseases such as obesity and diabetes. Multiple sclerosis seems to be confined to white people living far from the equator, and cancer of the oesophagus in South Africa mostly occurs among black people in the Eastern Cape. Undeniable facts must be faced and dealt with in a rigorous scientific manner. An open mind must be kept in the REC deliberations, where we are to learn and to submit strongly held views to the critical scrutiny of others from whom we should be prepared to learn. Race is not a straightforward social or biological 'fact'. Race will always be a contested concept which demands, for its legitimate acceptance or rejection in health care ethics, an open discussion which is executed and governed by the search for the best argument.

If the only force in democratic deliberation is rational argument, what counts as rational? Habermas writes: 'we call someone rational not only if he is able to put forward an assertion, and, when criticized, to provide grounds for it by pointing to appropriate evidence, but also if he is following an established norm and is able, when criticized, to justify his action by explicating the given situation in the light of legitimate expectations. ${ }^{34}$ However, the level of contestation by 
the notion of race may force an REC to indulge in what Habermas calls the 'discourse' of reconstructive science. Bernstein considers that this discourse is '... the type of elucidation and argumentation in which we suspend immediate action and in which participants seek to redeem the validity claims that have been challenged. "Discourse" is a term of art, a construct, an "ideal type" introduced to highlight the type of speech that is relevant for argumentative redemption of validity claims..35 Thus it might sometimes be necessary to reflect on our norms and values in deliberations about race to establish that we are on the same wavelength, are talking about the same thing, and are applying the same criteria when we evaluate arguments.

\section{Conclusion}

The REC should demand that the protocol provides a careful consideration of race as a factor in the selection of the study group. The central issue is whether, in spite of the 'potential social costs associated with linking race or ethnic background with genetics, ... these potential costs are outweighed by the benefits in terms of diagnosis and research. ${ }^{36}$ The REC cannot decide the relevance of race as variable in a study if this is not clear and persuasive.

It must be established how pivotal a factor race is, compared with other factors in the sample or group selection. Is race really an inherent characteristic that sample members should share, or is it of secondary importance? Is race not possibly, as the case study alludes, "like the side of the city on which people live ... a marker for differential experiences and exposures rather than a factor inherent to the person'? ${ }^{37}$

Is race identified as a marker, and have all other possible variables been taken in to account? Other possible variables include 'socioeconomic status, social class, personal or family wealth, environmental exposures, insurance status, age, diet and nutrition, health beliefs and practices, education level, language spoken, religion, tribal affiliation and country of birth.3.

Are the names assigned to groups acceptable to the groups themselves?

Finally, deliberation, especially about a controversial notion such as race, is arduous and will probably remain inconclusive. It is too much to expect this process to yield definitive truths. We can expect a series of (hopefully) progressive settlements that represent provisional beacons of insight to draw on in future conversations. Race cannot easily be settled and forgotten about in future; it represents tensions and contestations that will continue to permeate interpersonal contact and social relations in this country. Our challenge is to make it manageable and no longer feared or concealed. If continued deliberation cannot achieve that, nothing short of violence will.
References

1. Hegel GWF, as quoted by Bohman J. Public Deliberation: Pluralism, Complexity and Democracy. 1996. Cambridge, Mass: MIT Press, 1996: 239.

2. Habermas J. Communication and the Evolution of Society. London: Heinemann, 1979.

3. Habermas J. The Structural Transformation of the Public Sphere. Cambridge: Polity Press, 1989.

4. Habermas J. Between Facts and Norms: Contributions to a Discourse Theory of Law and Democracy. Cambridge, Mass: MIT Press, 1998

Rawls J. A Theory of Justice. Oxford: Oxford University Press, 1980

6. Elster J, ed. Deliberative Democracy. Cambridge: Cambridge University Press, 1998.

7. Bohman J. Public Deliberation: Pluralism, Complexity and Democracy. Cambridge, Mass: MIT Press, 1996.

8. Gutman A, Thompson D. Democracy and Disagreement. Cambridge, Mass: Harvard University Press,

9. Gambetta D. 'Claro': an essay on discursive machismo. In: Elster J, ed. Deliberative Democracy. Cambridge: Cambridge University Press, 1998: 19-43

10. Fearon JD. Deliberation as discussion. In: Elster J, ed. Deliberative Democracy. Cambridge: Cambridge University Press, 1998: 44-68.

1. Stokes S. Pathologies of deliberation, In: Elster J, ed. Deliberative Democracy. Cambridge: Cambridge University Press, 1998: 123 .

12. Gambetta D. 'Claro': an essay on discursive machismo. In: Elster J, ed. Deliberative Democracy. Cambridge: Cambridge University Press, 1998: 19.

13. Cohen J. Democracy and liberty. In: Elster J, ed. Deliberative Democracy. Cambridge: Cambridge University Press, 1998: 186.

14. Fearon JD. Deliberation as discussion. In: Elster J, ed. Deliberative Democracy. Cambridge: Cambridge University Press, 1998: 44-49.

Elster J, ed. Deliberative Democracy. Cambridge: Cambridge University Press, 1998: 8.

15. Elster J, ed. Deliberative Democracy. Cambridge: Cambridge University Press,

16. Rawls J. A Theory of Justice. Oxford: Oxford University Press, 1980: 136-141.
17. Habermas J. Communication and the Evolution of Society. London: Heinemann, 1979: 1-68. 17. Habermas J. Communication and the Evolution of Society. London: Heinemann, 1979: 1-68.
18. Bohman J. Public Deliberation: Pluralism, Complexity and Democracy. Cambridge, Mass: MIT Press,

1996: 238.
9. Rorty R. Objectivity, Relativism and Truth (Philosophical Papers, Vol. 1). Cambridge: Cambridge Rorty R. Objectivity, Relatist
University Press, 1991: 191.

20. Fearon JD. Deliberation as discussion. In: Elster J, ed. Deliberative Democracy. Cambridge: Cambridge University Press, 1998: 47.

1. Van Niekerk AA. 'The unexamined life is not worth living': Socratic dialogue versus Sophist debate at the birth of philosophy. Journal for Christian Scholarship 42, Special Edition 1: 189-200.

22. Gambetta D. 'Claro': an essay on discursive machismo. In: Elster J, ed. Deliberative Democracy. Cambridge: Cambridge University Press, 1998: 20-21.

23. Fearon JD. Deliberation as discussion. In: Elster J, ed. Deliberative Democracy. Cambridge: Cambridge University Press, 1998: 44-48.

24. Ncayiyana DJ. Racial profiling in medical research: what are we measuring? S Afr Med J Ne07:97(12):1225-1226.

25. Krog A. Begging to be Black. Cape Town: Random House Struik, 2009: 93-94.

26. Krog A. Begging to be Black. Cape Town: Random House Struik, 2009: 100

27. Krog A. Begging to be Black. Cape Town: Random House Struik, 2009: 122.

28. Krog A. Begging to be Black. Cape Town: Random House Struik, 2009: 267.

29. Krog A. Begging to be Black. Cape Town: Random House Struik, 2009: 238.

30. Bhopal R. Is research into ethnicity and health racist, unsound, or important science? BMJ 1997;314:1751-1756.

31. Bloche MG. Race based therapeutics. N Engl J Med 2004;351:2035-2037.

32. Hoover EL. There is no scientific rationale for race based research. J Natl Med Assoc 2007;99(6):690692

33. Schwartz RS. Racial profiling in medical research. N Engl J Med 2001;344:1392-1393.

4. Habermas J. The Theory of Communicative Action: Reason and the Rationalization of Society. 1984. London: Heinemann, 15.

35. Bernstein RJ. Beyond objectivism and relativism. 1983. Oxford: Blackwell: 186

36. Burchard EG, Ziv E, Coyle N. The importance of race and ethnic background in biomedical research and clinical practice. N Engl J Med 2003;348:1170-1175.

37. Jones CP. Invited Commentary: 'Race', racism and the practice of epidemiology. Am J Epidemiol 2001;154(4):299-304.

39. Caulfield T, Fullerton SM, Ali-Khan SE, et al. Race and ancestry in biomedical research: exploring the challenges. Genome Medicine 2009;1(21 January 2009):8.1-8.8.

Accepted 12 January 2011. 